\title{
Minimum degree of shear connection in composite beams in buildings
}

\author{
E. S. Aggelopoulos ${ }^{\mathrm{a} *}$, G. H. Couchman ${ }^{\mathrm{a}}$ and R. M. Lawson ${ }^{\mathrm{a}, \mathrm{b}}$ \\ ${ }^{a}$ The Steel Construction Institute (SCI), UK \\ bepartment of Civil and Environmental Engineering, University of Surrey, UK \\ *corresponding author, e-mail address: e.aggelopoulos@steel-sci.com
}

\begin{abstract}
Composite beams are often used in building construction with spans normally ranging between 6 to $18 \mathrm{~m}$. They are commonly used together with decking of 50 to $80 \mathrm{~mm}$ depth that spans 3 to $4.5 \mathrm{~m}$ between the beams. Rules for the minimum degree of shear connection in composite beams are presented in Eurocode 4 and other international Codes, and were derived for beams propped in construction.

Eurocode 4 defines a minimum limit for the degree of shear connection, primarily to ensure that slip at the steel-concrete interface does not exceed a limiting value. This limit is proportionate to the beam span and also depends on the steel grade and the asymmetry in the flange areas of the section. Currently, many designs cannot achieve the codified minimum degree of shear connection, since it is not possible to accommodate a sufficient number of shear connectors on the span as dictated by the spacing of the deck ribs. However, there are special cases which are not explicitly accounted for in Codes. This paper aims to investigate the degree of shear connection requirements in such cases, including beams that are unpropped in construction, beams that are not fully utilised in bending because serviceability criteria govern their design and beams that are predominantly loaded by point loads rather than uniform loading.

Parametric finite element (FE) analyses were carried out for composite beams in the span range of 9 to $18 \mathrm{~m}$ and the results are presented. The finite element models have been validated against composite beam tests. Comparisons are made with the current Eurocode 4 provisions and modifications are proposed where appropriate.
\end{abstract}

Keywords: Buildings; Structures \& design; Codes of practice \& standards; Composite structures.

\section{Introduction}

Composite construction currently represents approximately $40 \%$ of the non-residential multistorey building market in the UK. Composite floors offer significant advantages over solid concrete slabs such as weight savings and speed of construction since the decking also acts as formwork. Composite beams, in particular, are structurally efficient and longer spans of 15 to $20 \mathrm{~m}$, which are beneficial for office buildings, can be achieved.

The design of composite beams is covered by EN 1994-1-1 [1], as well as the former BS 59503.1 [2] and the AISC 360-10 [3]. These Codes provide guidance for the design at the Ultimate and Serviceability Limit States (ULS and SLS, respectively), including rules for achieving sufficient shear connection (i.e. connection between the slab and the steel section). Shear connection is normally provided through the use of headed stud shear connectors welded to the steel section.

Full shear interaction, to ensure fully composite action (strain compatibility) between the steel section and the slab, is not practically possible. In reality there is going to be a displacement of the slab relative to the steel section (along their interface), which is known as slip. The majority of Codes dealing with building structures provide rules for partial shear connection, but at the same time they limit its 
extent to control slip so that the slip capacity of the shear connectors is not exceeded.

Codes define the degree of shear connection as the ratio of the sum of the resistances of the shear connectors to the smaller of the axial resistance of the slab and that of the steel section. Codified limits on the degree of shear connection recognise the variation in the build-up of slip with the steel grade, asymmetry of the steel section and also the span.

However, other parameters such as the method of construction (propped or unpropped), the loading type and the utilisation in bending have been known to have an effect on the minimum degree of shear connection requirements in composite beams [4,5]. In order to investigate and quantify the effect of each of these variables on the degree of shear connection requirements, parametric FE analyses were carried out.

\section{FE modelling and analysis}

Different span and steel section depth combinations were considered for each parameter under investigation. The minimum degree of shear connection (below which the slip capacity of the shear connectors is exceeded) was determined for an applied load in each analysis that is within 5\% of the plastic bending resistance of the beam for the particular degree of shear connection. Therefore, the slip for various degrees of shear connection was calculated at a level of load corresponding to the attainment of $95 \%$ of the plastic bending resistance $\left(\mathrm{M}_{\mathrm{pl}}\right)$ of the beam. This is consistent with the assumptions made in the original studies for the calibration of the shear connection rules of EN 1994-1-1 [6]. The degree of shear connection that gave a slip not greater than $6 \mathrm{~mm}$, which is the assumed slip capacity as quantified in EN 1994-1-1 for 'ductile' connectors, was recorded (accounting for partial material factors as would be the case in practical design).

\subsection{Model description}

The FE modelling and analysis were carried out using the software ANSYS. Beam elements were used to represent both the rectangular concrete flange (the depth of slab above the decking only) and the steel beam (using a subset to input different section sizes).
The beam was modelled as simply supported, with the slab restrained horizontally (in the direction of the beam axis) at the centre point. The slab width was equal to the effective width (the minimum of span/4 or the beam spacing which was chosen taking into account the span capability of the decking), to ensure that the same contribution of concrete is used in the model as that used in design. All nodes and elements were restrained from moving out-ofplane, or rotating along any of the in-plane axes.

Rigid elements were used to join the beam and slab elements at the shear connector positions, and these were broken at the interface between the beam and slab with nonlinear springs that were constrained to move only parallel to the beam. These springs initially had zero length. The load-slip behaviour of the shear connector springs was defined using a bilinear model with an initial gradient (elastic part) and a plateau being reached at the resistance value of the shear connector.

A bilinear material model was used for steel with the Young's modulus taken as $210 \mathrm{kN} / \mathrm{mm}^{2}$ and linear strain hardening after yielding (E/100 slope was assumed in accordance with EN 19931-5 [7]). A bilinear model was also used for concrete, with an initial gradient equal to the modulus of elasticity (taken as $21 \mathrm{kN} / \mathrm{mm}^{2}$ to reflect combined short- and long-term loading) and a plateau in compression at $0.85 f_{\mathrm{c}}$ (where $f_{\mathrm{c}}$ is the compressive strength of concrete). For concrete in tension, where cracking would normally occur, a plateau at $10 \%$ the compressive plateau was used. A calibration exercise showed that the effect of the magnitude of this plateau on the load-deflection behaviour of the model was insignificant, but limiting the strain in tension would prematurely stop the model from converging.

\subsection{Model validation against tests}

The model was validated against an $11.2 \mathrm{~m}$ span asymmetric beam test carried out as part of the DISCCO project [8]. The steel section was $450 \mathrm{~mm}$ deep with a $180 \times 10$ top flange, $180 \times 15$ bottom flange and $10 \mathrm{~mm}$ thick web. Steel grade was S355 with a measured yield strength of $400 \mathrm{~N} / \mathrm{mm}^{2}$ which was used in the analysis. The target concrete strength was $30 \mathrm{~N} / \mathrm{mm}^{2}$. At 7 days and 14 days, the strength was measured as $16.6 \mathrm{~N} / \mathrm{mm}^{2}$ and $20.1 \mathrm{~N} / \mathrm{mm}^{2}$, respectively, which was slightly lower than anticipated. FE analyses were run assuming both the design 
concrete strength $\left(30 \mathrm{~N} / \mathrm{mm}^{2}\right)$ and a reduced concrete strength of $20 \mathrm{~N} / \mathrm{mm}^{2}$, but the difference in the results was insignificant. The slab was $150 \mathrm{~mm}$ deep with $80 \mathrm{~mm}$ deep trapezoidal decking and single (one per trough) $19 \times 125$ studs at $300 \mathrm{~mm} \mathrm{c} / \mathrm{c}$. The width of the slab was equal to the effective width of $2.8 \mathrm{~m}$. Unpropped construction conditions were simulated in the lab.

The shear connector resistance was taken as $68 \mathrm{kN}$ which agrees well with push-out test data and the back-analysis of other beam tests with identical slab/stud configurations and similar material properties [8]. The degree of shear connection was $33 \%$, based on this shear connector resistance and measured material properties. The shear connector elastic stiffness was assumed to be $70 \mathrm{kN} / \mathrm{mm}$ which also correlates with the experimental observations of [8] as shown in [9]. This is different to the value assumed in some of the parametric analyses presented in this paper $(100 \mathrm{kN} / \mathrm{mm})$, but this was shown not to have a significant effect on the results overall, as expected.

The comparisons presented in Fig. 1 in terms of the load-deflection response of the beam and the end slip development with loading demonstrate the good agreement between the FE model and the test. The slip results, which are most important for the purposes of the present study, exhibit excellent agreement with the test.

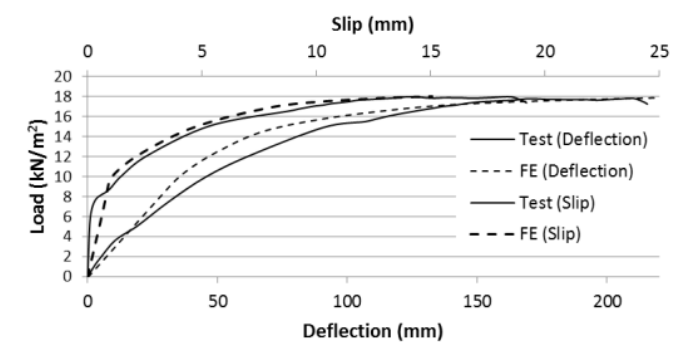

Fig. 1. Comparisons between experimental and FE results for the $11.2 \mathrm{~m}$ span beam test.

\section{Special cases of significance in terms of the shear connection requirements}

\subsection{Unpropped beams}

Beams that are unpropped during construction (definition of unpropped given in EN 1994-1-1, 1.5.2.1) will have a different strain distribution in the steel section when compared to propped beams, but the slip will generally be less because part of the loading is applied in the non-composite stage. Therefore, a lower degree of shear connection compared to propped beams could be justified. This is recognised in SCI P405 [10] where modified shear connection rules for unpropped beams (amongst other cases) are presented for use in the UK.

Typical bending moment vs slip FE results are shown in Fig. 2 for a $12 \mathrm{~m}$ span beam constructed both unpropped and propped. The degree of shear connection for this example was $46 \%$ approximately, based on design material properties. The plastic moment of resistance $\mathrm{M}_{\mathrm{pl}}$ as well as $0.95 \mathrm{M}_{\mathrm{pl}}$, the significance of which was explained earlier, are also plotted on the graph. The difference in slip development is obvious and, unlike the unpropped beam which is almost adequate (slip just over $6 \mathrm{~mm}$ at $0.95 \mathrm{M} \mathrm{pl}$ ), the propped beam would require a significantly higher degree of shear connection to limit slip to less than $6 \mathrm{~mm}$ at $0.95 \mathrm{M}_{\mathrm{pl}}$ as per codified requirements. The minimum degree of shear connection based on EN 1994-1-1 for this particular case is $61 \%$.

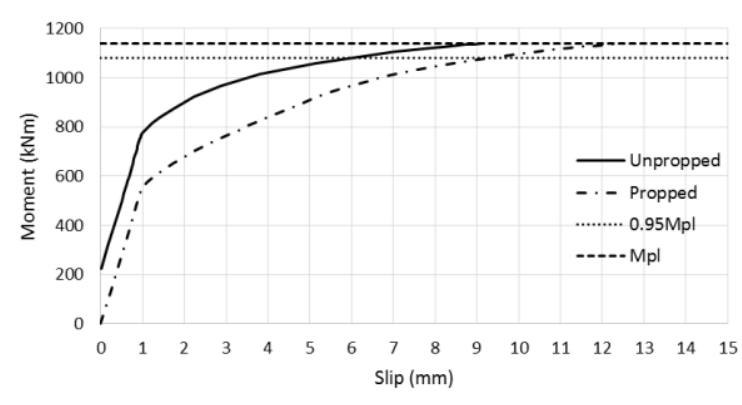

Fig. 2. Bending moment vs end slip results obtained from FEA for a $12 \mathrm{~m}$ span composite beam.

The maximum strain in the bottom flange of the steel section is plotted in Fig. 3 for the same example. As shown, there is significant build-up of plastic strain in the final stages of loading, while the strain in the bottom flange at $0.95 \mathrm{M}_{\mathrm{pl}}$ is between 2.5 and 3 times the yield strain.

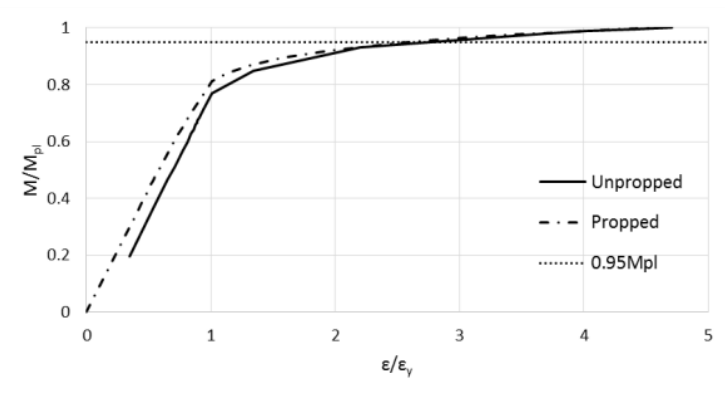

Fig. 3. Development of strain in the bottom flange of the beam obtained from FEA. 
The degree of shear connection required to limit slip to below $6 \mathrm{~mm}$ for three different spans (9 $\mathrm{m}, 12 \mathrm{~m}$ and $15 \mathrm{~m}$ ) was determined from the FEA and the results are plotted in Fig. 4 for unpropped construction. The parameters used in the analyses are presented in Table 1 . The slab configuration and the shear connector characteristics used were as described in section 2.2. The proportion of the weight applied at the construction stage over the maximum load (corresponding to $\mathrm{M}_{\mathrm{pl}}$ ) was of the order of 10$17.5 \%$ in the analyses. The degree of shear connection required by EN 1994-1-1 (for propped beams) as well as that calculated using Eq. 1 are also plotted in Fig. 4. The latter was developed from the work leading to [10] for unpropped symmetric beams loaded with uniformly distributed imposed load on the floor (i.e. $\gamma_{Q} q_{k}$ ) not exceeding $9 \mathrm{kN} / \mathrm{m}^{2}$. As shown, Eq. 1 correlates well with the FE results.

$\eta \geq 1-\left(\frac{355}{f_{y}}\right)(0.802-0.029 L)$ but $\eta \geq 0.30$

The reason for the lower bound mínimum degree of shear connection of $30 \%$ in Eq. 1 is to ensure that the shear connection remains elastic under serviceability levels of loading and avoid irreversible deformations under repeated loading $[9,10]$. The lower bound mínimum degree of shear connection in [10] is higher for other cases such as propped beams and asymmetric beams. The lower bound mínimum degree of shear connection in EN 1994-1-1 is set to $40 \%$.

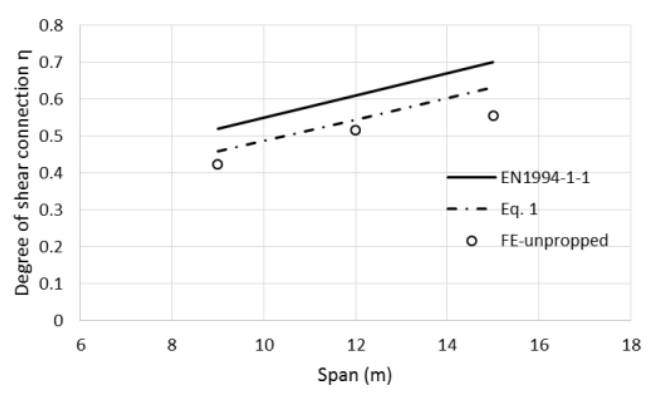

Fig. 4. Shear connection requirements for unpropped beams.

Table 1. Parameters used in the FE study

\begin{tabular}{cccc}
\hline $\begin{array}{c}\text { Span L } \\
(\mathbf{m})\end{array}$ & $\begin{array}{c}\text { Steel } \\
\text { section }\end{array}$ & $\begin{array}{c}\text { Steel } \\
\text { grade }\end{array}$ & $\begin{array}{c}\text { Concrete } \\
\text { grade }\end{array}$ \\
\hline 9 & IPE400 & & \\
12 & IPE500 & S355 & $\mathrm{C} 25 / 30$ \\
15 & IPE600 & &
\end{tabular}

\subsection{Beams partly utilised in bending}

Current minimum degree of shear connection rules in EN 1994-1-1 are conservative for composite beams that are not fully utilised in bending in ULS due to serviceability considerations governing their design. This becomes evident from Fig. 2 which shows a significant increase of slip at higher loads, i.e. when the resistance of the beam is approached.

The parametric FE analyses demonstrated that, for composite beams with low utilisation ratios in bending, lower degrees of shear connection than the minimum required in accordance with EN 1994-1-1 would still be acceptable. Fig. 5 presents results in the form of a multiplication factor that may be applied to the minimum degree of shear connection from EN 1994-1-1. These results are for propped, symmetric beams and suggest that for configurations with proven ductility of the shear connectors, i.e. slip capacity of at least $6 \mathrm{~mm}$, this factor may be taken equal to the bending utilisation ratio squared $\left(M_{\mathrm{Ed}} / M_{\mathrm{Rd}}\right)^{2}$. However, a lower bound minimum degree of shear connection is also applicable for the reasons stated in the previous section and appropriate cut-off values are presented in [10] for different cases.

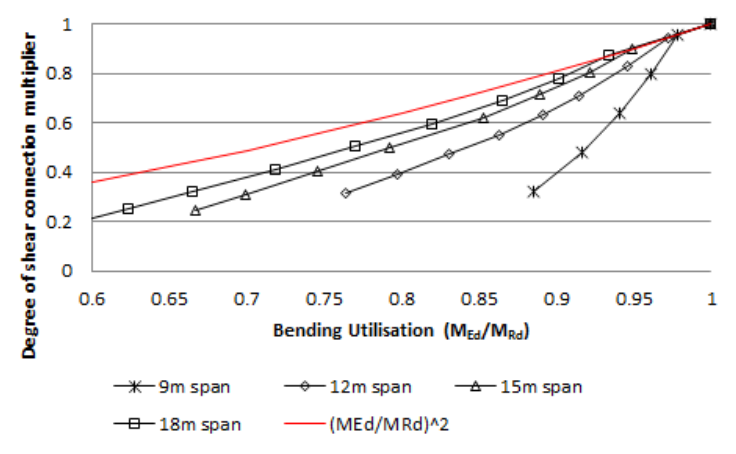

Fig. 5. EN 1994-1-1 degree of shear connection multiplier for beams partly utilised in bending.

\subsection{Beams with heavier than normal loads}

In some cases, e.g. plant rooms, the imposed loading can be considerably higher than typical office building applications. The implication this has is of greater importance for beams that are unpropped in construction, although propped beams are also affected. The current codified minimum degree of shear connection requirements were developed assuming lighter steel sections at higher span:depth ratios than the ones required to support heavier imposed loads, 
so they may not be applicable in all cases. Composite beams are normally designed for 2.5 to $5 \mathrm{kN} / \mathrm{m}^{2}$ unfactored loads, while the span:depth ratio for the steel section typically ranges from 22 to 25 . For more heavily loaded beams (of the order of $8 \mathrm{kN} / \mathrm{m}^{2}$ unfactored load) the steel section will be heavier, with a span:depth ratio close to 20 or less. FE analyses have shown that the use of a heavier steel section necessitates the use of more onerous rules for the minimum degree of shear connection.

Fig. 6 compares the degree of shear connection for propped construction and $6 \mathrm{~mm}$ allowable slip according to EN 1994-1-1 and that obtained from FE analyses. The same configurations shown in Table 1 were used in the analyses with the exception of span:depth ratio (L/d) which was equal to 20 . The results from using Eq. 2, which was developed from the work leading to [10] for beams loaded with heavier than normal loads (up to $8 \mathrm{kN} / \mathrm{m}^{2}$ unfactored or $12 \mathrm{kN} / \mathrm{m}^{2}$ factored imposed loading), are also plotted.

$\eta \geq 1-\left(\frac{355}{f_{y}}\right)(0.855-0.048 L)$ but $\eta \geq 0.40$

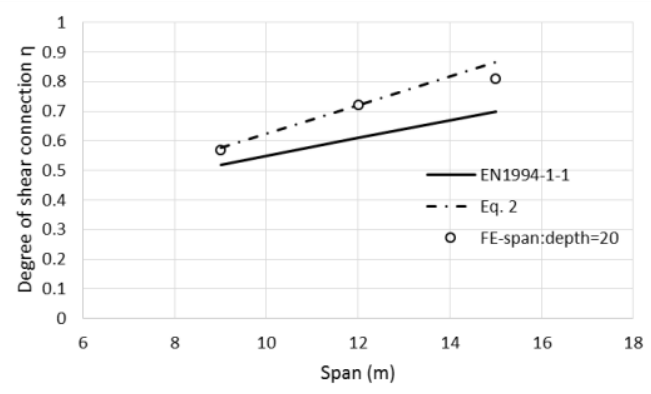

Fig. 6. Shear connection requirements as a function of span:depth ratio.

\subsection{Beams with point loads}

Beams with point loads are subject to relatively high shear forces compared to uniformly loaded beams and their span:depth ratio is generally in the range of 18 to 22 . It is often the case that the main design criteria are those of vertical shear and longitudinal shear.

For a beam subject to a single central point load it was shown that the required deformation capacity of the shear connectors is much less than for a uniformly loaded beam [5]. Where a beam is subject to an off-centre point load, the shear force is clearly higher on one side of the beam, which influences the longitudinal shear flow, as also shown in [4]. More shear connectors are therefore required on one side of the beam than the other. It is normally essential that the point load remains in the middle half or even third of the span.

A simply supported beam subject to two point loads experiences uniform shear flow in the outer parts of the span and zero or low shear flow in the middle part. The critical cross-section is at the position of a point load and therefore all the required shear connectors should be distributed at equal spacing over the distance between the nearer support and the point load. The shear connectors in the middle part of the span could be placed at nominal spacing, as they are not subject to high shear forces.

Analysis of beams with combined uniform loading and point loads is complicated because of the number of variables to consider. Beams with multiple point loads tend to the case of uniform load, and shear flow is constant between the point load positions. The results from FE analyses on point-loaded beams and their comparison against beams with uniform loading are presented in this section. The most common loading arrangement is when the loads are positioned at a distance $1 / 3$ the beam span from each support, but the case where a beam is loaded by a single point load at mid-span is also considered.

The loading pattern in composite beams loaded with point loads rather than uniform loading can be beneficial in terms of shear connection requirements. Analytical results [4] suggest that shear connection requirements are potentially less severe for a beam with point loads at 1/4 span positions; the degree of shear connection required may be even lower for a beam with a single point load at mid-span. These observations are also demonstrated in Fig. 7, which shows the development of slip with increasing moment for beams with uniform loading or point loads at mid-span or at $1 / 3$ span positions. This is for a $12 \mathrm{~m}$ span beam modelled using similar properties as the ones mentioned earlier. The degree of shear connection (equivalent to the requirement of EN 1994-1-1 for this particular span) was the same for all three scenarios at the critical section. As shown, for the cases with point loads the shear connectors exhibit significantly less slip. 
The results of Fig. 7, though encouraging for beams with point loads, do not justify on their own a change to the current rules, also because point loads often coexist with uniform loading on the beam. Furthermore, with point loads, situations of asymmetrically loaded beams may be a more frequent occurrence and such cases will have to be considered separately. It is therefore recommended that the same rules apply for uniform loads and point loads when only the shear connectors from the end to the point of maximum moment are considered in design.

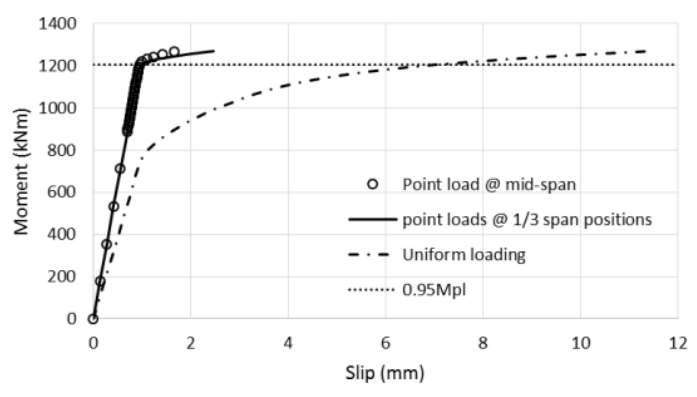

Fig. 7. Bending moment vs end slip plots for a $12 \mathrm{~m}$ span beam loaded with a) UDL, b) a single point load at mid-span and c) two point loads at $1 / 3$ span positions.

\section{Conclusions}

This paper presents findings that demonstrate the effect of certain parameters on the degree of shear connection that are not currently covered by EN 1994-1-1. The method of construction (propped and unpropped) is shown to have an effect on shear connection demands and unpropped beams require less shear connection, provided the self-weight of the beam and the wet concrete applied at the construction stage is a good proportion of the total load.

For beams that are not fully utilised in bending and serviceability criteria govern their design, a relaxation in the shear connection requirements is also justified. This is because large amounts of slip only occur in the final stages of loading and particularly when the plastic bending resistance of the beam is approached. Modification of the current EN 1994-1-1 minimum degree of shear connection rules as a function of the utilisation ratio in bending is therefore suggested.

Point loaded beams are also shown to require considerably less shear connection when compared to uniformly loaded beams. However, it is difficult to provide separate rules due to their coexistence with uniform loads and also due to the potential occurrence of largely asymmetrical loading on the beam.

The steel section size has been found to affect the shear connection requirements and the current rules may be applicable to a certain range of span:depth ratios (although this also depends on the overall proportions of the steel section and not just the span:depth ratio). Separate rules are proposed for cases where the applied imposed loading exceeds $6 \mathrm{kN} / \mathrm{m}^{2}$ (unfactored), which is when relatively heavy steel sections are likely to be used. Although these rules are more onerous than the ones in EN 1994-1-1, the designer can still take advantage of the low utilisation of the beam in bending as explained in this paper to overcome potential difficulties in achieving certain practical designs.

In cases where the proposed degree of shear connection limits lead to a lower degree of shear connection than that required by EN 1994-1-1, the effects of partial interaction (influence of slip) should be considered when calculating the deflection of the beam. This is covered in detail in both [9] and [10].

\section{References}

[1] European Committee for Standardisation (CEN). EN 1994-1-1, Eurocode 4. Design of composite steel and concrete structures - Part 1-1: General rules and rules for buildings. Brussels; 2004.

[2] British Standards Institution (BSI). BS 59503.1+A1. Structural use of steelwork in buildings. Design in composite construction. Code of practice for design of simple and continuous composite beams. London; 2010.

[3] American Institute of Steel Construction (AISC). ANSI/AISC 360-10. Specification for Structural Steel Buildings. Chicago, Illinois; 2010.

[4] Banfi M. Slip in composite beams using typical material curves and the effect of changes in beam layout and loading. Proceedings of Composite Construction in Steel and Concrete V Conference. South Africa; 2004.

[5] Johnson RP, Molenstra IN. Partial shear connection in composite beams for buildings. Proceedings of the Institution of Civil Engineers Part 2 1991;91(4):679-704.

[6] Aribert J-M. Analyse et formulation pratique de l'influence de la nuance de l'acier du profile sur le degre minimum de connexion partielle d'une poutre mixte. Construction Métallique 1997;3:39-55 (in French).

[7] European Committee for Standardisation (CEN). EN 1993-1-5, Eurocode 3. Design of steel 
structures - Part-1-5: General rules - Plated structural elements. Brussels; 2006.

[8] Research Fund for Coal and Steel (RFCS). Development of improved shear connection rules in composite beams (DISCCO). Grant Agreement RFSR-CT-2012-00030, Brussels; 2017.

[9] Lawson RM, Lam D, Aggelopoulos ES, Nellinger S. Serviceability performance of steel- concrete composite beams. Proceedings of the Institution of Civil Engineers - Structures and buildings 2016;170(2):98-114.

[10]Couchman G. Minimum degree of shear connection rules for $\mathrm{UK}$ construction to Eurocode 4. SCI Publication P405. Ascot, UK; 2015. 